\title{
ANALYSIS ON THE IMPACT OF INVESTMENTS, ENERGY USE AND DOMESTIC MATERIAL CONSUMPTION IN CHANGING THE ROMANIAN ECONOMIC PARADIGM
}

\author{
Gheorghe H. POPESCU ${ }^{1}$, Jean Vasile ANDREI ${ }^{*}$, Elvira $\mathrm{NICA}^{3}$, \\ Mihai MIEILA $\breve{A}^{4}$, Mirela PANAIT ${ }^{2}$ \\ ${ }^{1}$ Department of Finance and Banking, Dimitrie Cantemir Christian University, Bucharest, Romania \\ ${ }^{2}$ Faculty of Economic Sciences, Petroleum - Gas University of Ploiesti, Ploiesti, Prahova, Romania \\ ${ }^{3}$ Faculty of Administration and Public Management, Bucharest Academy of Economic Studies, \\ Bucharest, Romania \\ ${ }^{4}$ Faculty of Economic Sciences, Valahia University, Targoviste, Romania
}

Received 13 October 2017; accepted 15 September 2018

\begin{abstract}
The main aim of the paper is to assess the impact of fix capital, energy use and domestic material consumption in changing the inland Romanian economic paradigm, from an economic perspective, using the intensive form of the Cobb-Douglas function. In order to identify various connections of economic growth, sustainable development, energy usage has determined the application of the vector error correction (VEC) model and the implied error correction term (ECT). This method was chosen based on the premise that it has a high degree of applicability and it can be used in order to revile significant aspects terms of indicator significance and displays. The results obtained during the research confirm that both in Romania and at EU-28 level there are determinant and significant elements shaping a proactive economic policy.
\end{abstract}

Keywords: economic development, energy use, fixed capital stock, domestic material consumption, Cobb-Douglas, technological changes, economic policy.

JEL Classification: C15, C19, E22, P00, P18.

\section{Introduction}

Sustainable economic development is based on an effective economic policy that ensures an optimal interaction between all the economic sectors and the environmental restrictions. Specifically, the socio-economic development should be in a permanent process of continuity, provided, not to affect the environment and to protect the natural resources necessary to human existence. Identifying the linkage between investments, energy use and domestic material consumption and their effects on creating new economic value added, represents

${ }^{\star}$ Corresponding author. E-mail: andrei_jeanvasile@yahoo.com

This is an Open Access article distributed under the terms of the Creative Commons Attribution License (http://creativecommons. org/licenses/by/4.0/), which permits unrestricted use, distribution, and reproduction in any medium, provided the original author and source are credited. 
a determinant topic of research in field of economic theory, bringing into discussion new perspectives on valuing the advantages and costs of combining these dimensions in achieving of a sustainable economic development. The impact of investments, energy use and domestic material consumption in changing of the Romanian economic paradigm is still considered to be an understudied area, despite of numerous existing literature in the field. Understanding of the dynamics and correlations between investments, energy use and domestic material consumption may offer a wider perspective upon the energy economic research and impact on Romanian economy, being in the same time a cornerstone in arguing and designing the new environmental and energy policy paradigm. Energy and domestic material consumption define limiting factors of growth, and any disturbance in supplying diminishes the economic performance and the sustainability of the production process.

The numerous studies published in the field are centered in analyzing the exiting correlations between energy and different components or variables affecting the economic growth. As in literature (Soava, Mehedintu, Sterpu, \& Raduteanu, 2018; Clark, 2017; Panayotou, 2016; Sachs, 2015), in contemporary and well functional economies, the environmental protection represents a major objective as political, societal and academic approach. Despite the numerous technological changes, massive investments, and the new European environmental paradigm developments, environmental protection continues to be one of the most unconvergent policies and imposes numerous debates. Achieving a well and high functional free market economy in Romania, has imposed a massive and complex process of reforms during the last period. The transitional process implied a redesign of the inland economy, with different effects on economic sectors, implying ample transformations of the national economic paradigm. Also, the evolution of energy use and domestic material consumption bring into attention the necessity of a sustainable and continuous investment process in the economy in order to increase the economic efficiency and competitiveness. As it is argued in literature (Zaharia, Pătrașcu, Gogonea, Tănăsescu, \& Popescu, 2017; Lan-yue et al., 2017; Pang, Deng, \& Hu, 2015), energy is an essential component in assuring economic development and its consumption has rapidly increased during the last period, as a marker economic growth (Ahmed \& Azam, 2016; Bastola \& Sapkota, 2015).

Currently, the modern economies experience a period that may be characterized by two major restrictions: first, the economic restriction, induced by increasing population with growing demands, aimed to improve their life conditions; and second, but not least, the required economic growth has to be achieved amid the worsening of the global economic situation. The policies already in place proved the effectiveness of the environmental taxes as one of the main tools in orientation of the economic development towards sustainability, via two main action directions: the improvement of the energy productivity and growing the installed power of the plants based on renewable sources, especially wind and solar.

From the perspective of optimizing the performance of the national economic system, energy is remarked and domestic material consumption defines core components which must be carefully analyzed and understanded in order to define the most appropriate prediction production process. The technical innovation and the industrial structure of the economy seriously outline the dimension of these variables. From this perspective, the modality of reducing the both the energy use and domestic material consumption are hot issues for any free market economy. 
Concerning the energy productivity, previous researches pointed out, particularly in cases of developed economies, a decoupling of the economic growth both from energy consumption and from energy taxation. According to Payne's theory (Payne, 2010), the results of above studies confirm the conservative hypothesis in case of Romania and the hypothesis of neutrality in case of European Union (Andrei, Mieilă, Popescu, Nica, \& Manole, 2016; Popescu, Mieilă, Nica, \& Andrei, 2018). Moreover, in case of Romania there has been pointed out the existence of a causality relationship from GDP to taxation, which may be considered as a reverse situation (Andrei et. al., 2016).

Assuming that the GDP per capita is the most important indicator of economic growth (Huang, Hwang, \& Yang, 2008; Costanza, Hart, Talberth, \& Posner, 2009; Zilio \& Recalde, 2011), the changes analyzed for fixed capital stock per worker, energy use and domestic material consumption are the most significant. Also, taking into account the data available for this research, the paper was mainly focused on the period 1994-2014. In the first part of the research, has been analyzed the evolution of the four indicators considered within the study.

The main objective of this paper is to identify and highlight the qualitative aspects of Romanian economic policies and their effects on transforming the inland economic paradigm. On the other hand, the authors tried to identify the characteristics of the evolution of the three indicators, and the extent to which quantitative assessments are statistically significant at the inland economy. The research is based on the latest available datasets from various sources (World Bank Database, 2018a, 2018b; International Labour Organization [ILO], 2018; National Institute of Statistics of Romania [NIS], 2018), further explained. In the Table 1 below placed, are presented the data series besides the used symbols, a short description, and the data availability period for each of the considered series.

There has to be noticed that the data regarding the GDP per capita, available in the World Bank Database (World Bank Database, 2018b) in constant figures, the base year depends upon the country, and is not provided. The fixed capital stock per worker is result of considering the total tangible fixed assets, provided by the National Institute of Statistics of Romania (NIS, 2018), the population available in the World Bank Database (WBD), and the labour participation rate, provided by the International Labour Organization [ILO] (2018).

Although the evaluation of the tangible fixes assets using the perpetual inventory method, based on the data regarding the gross fixed capital formation available in international databases could represent another approach, the authors considered the employing of the actual data as the most suitable option. The descriptive plots of the data series are presented in the Figures 1-4. The common period of data availability is 1994-2014.

Examining the Figures 1-4 there are noticeable improvements of the overall economic situation, expressed by the steady increase of the GDP per capita, which almost doubled within the analyzed period, simultaneously with the diminution of the energy use, which reduced by more than one-third in the analyzed period. However, there might be observed that the evolution of the energy use has actually the shape of "saw teeth", amid a slight diminution trend, proved also by the diminution trend in the regression slope. This may be the result of the Romanian economic conjuncture, still in a transitory situation characterized by restructuring of the consumption patterns (Andrei et al., 2016). In case of fixed capital stock per worker during the range 1990-1997 the management of the transition processes induced 
a massive decapitalization of the economy, followed by an upward trend; 2004 was the first year when the indicator exceeded the value recorded in 1990. However, as the common time range begins with 1994 there has been considered that this situation will not influence the results of the current analysis.

Table 1. Data series and sources (source: authors based on Eurostat, 2018; ILO, 2018; NIS, 2018; World Bank Database, 2018a, 2018b)

\begin{tabular}{|c|l|c|}
\hline Symbol & \multicolumn{1}{|c|}{ Description of the Variable } & $\begin{array}{c}\text { Time-period } \\
\text { availability of the data }\end{array}$ \\
\hline Y & GDP per capita (constant Local Currency) (World Bank Database) ${ }^{1}$ & $1990-2015$ \\
\hline K & Fixed capital stock per worker (constant 1990 RON) ${ }^{2}$ & $1990-2016$ \\
\hline EG & $\begin{array}{l}\text { Energy use (kg of oil equivalent per capita) (World Bank Database, } \\
2018 a)^{3}\end{array}$ & $1971-2014$ \\
\hline MC & Domestic material consumption (in tonnes per capita) $^{4}$ & $1994-2014$ \\
\hline
\end{tabular}

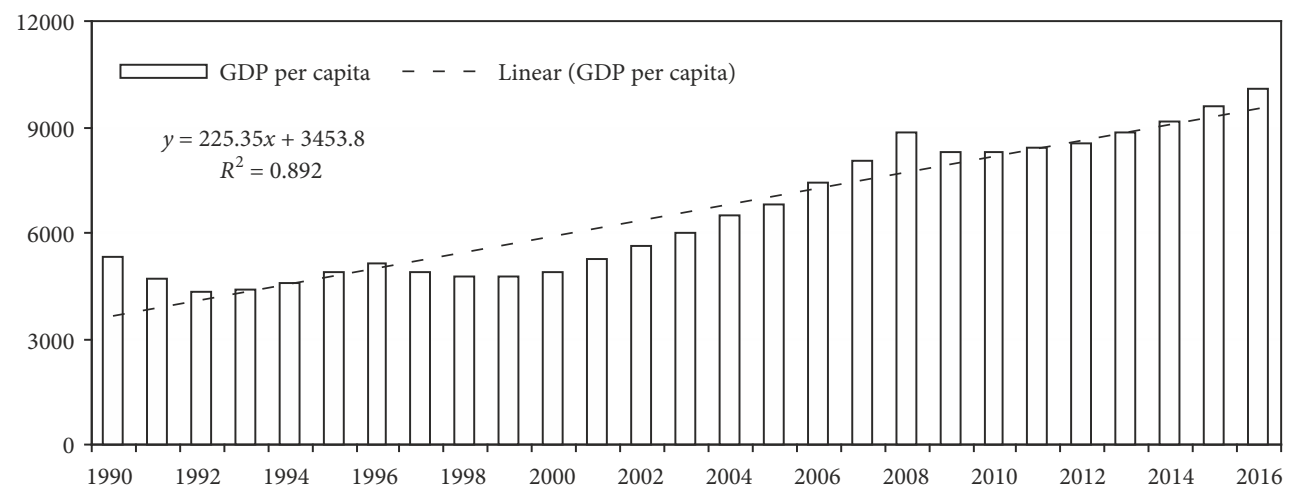

Figure 1. GDP per capita (constant 2010 US\$)

(source: authors based on World Bank Database, 2018a)

\footnotetext{
${ }^{1}$ GDP at purchasers' prices is the sum of gross value added by all resident producers in the economy plus any product taxes and minus any subsidies not included in the value of the products. It is calculated without making deductions for depreciation of fabricated assets or for depletion and degradation of natural resources (World Bank Database, 2018b).

${ }^{2}$ Gross fixed capital formation (formerly gross domestic fixed investment) includes land improvements (fences, ditches, drains, and so on); plant, machinery, and equipment purchases; and the construction of roads, railways, and the like, including schools, offices, hospitals, private residential dwellings, and commercial and industrial buildings. $\mathrm{RON}=$ the Romanian national currency (Romanian New Leu) (NIS, 2018).

${ }^{3}$ Energy use refers to use of primary energy before transformation to other end-use fuels, which is equal to indigenous production plus imports and stock changes, minus exports and fuels supplied to ships and aircraft engaged in international transport (World Bank Database, 2018a).

${ }^{4}$ The domestic material consumption (DMC) measures the total amount of material directly used by an economy. This indicator is defined as the direct material input (DMI) minus all physical exports. The DMI measures the direct input of materials for the use in the economy and equals to domestic extraction (DE) plus all physical imports. DMC is based on the economy-wide material flow accounts (EW-MFA). DMC in tonnes per capita provides an indication of the comparable material consumption of nations normalised with the population (Eurostat, 2018). $\mathrm{http}: / /$ ec.europa.eu/eurostat/tgm/table.do?tab=table\&init=1\&plugin=1\&language $=$ en \&pcode=t2020_rl110
} 


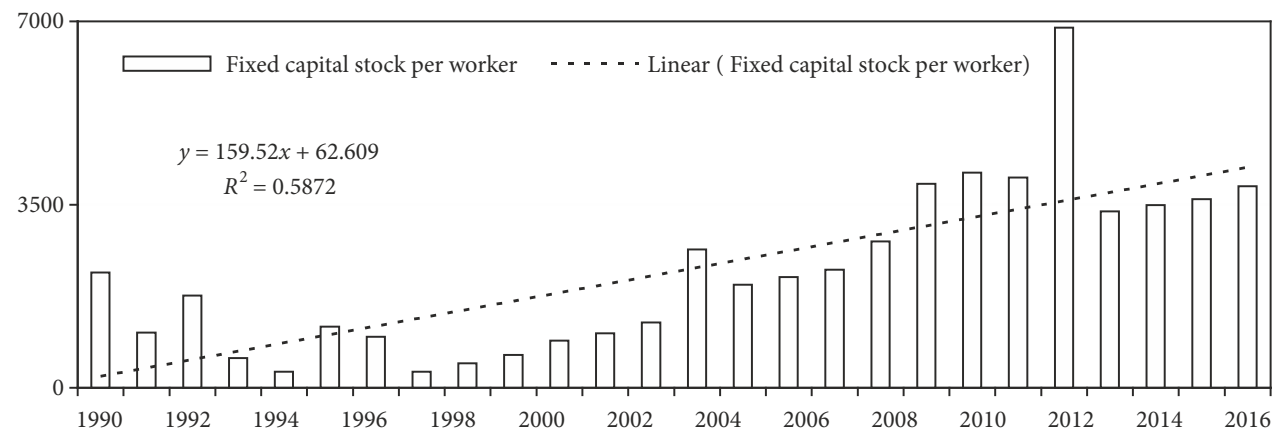

Figure 2. Fixed capital stock per worker (constant 1990 RON)

(Data sources: WBD, ILO, NIS, and authors' processing)

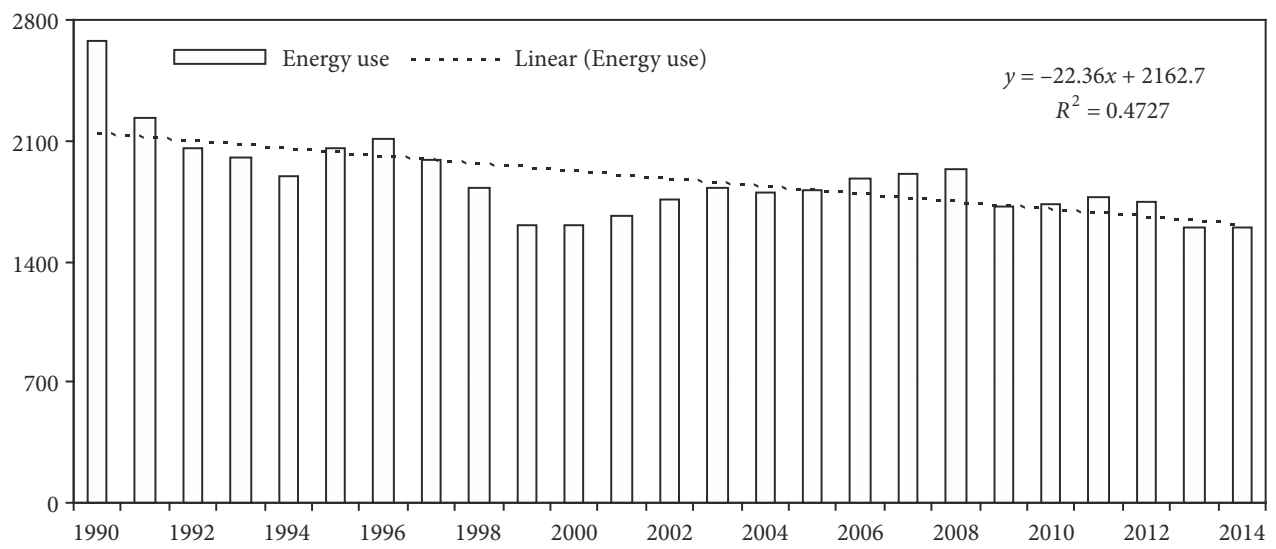

Figure 3. Energy use (kg of oil equivalent per capita Data source: WBD) (source: authors based on World Bank Database, 2018b)

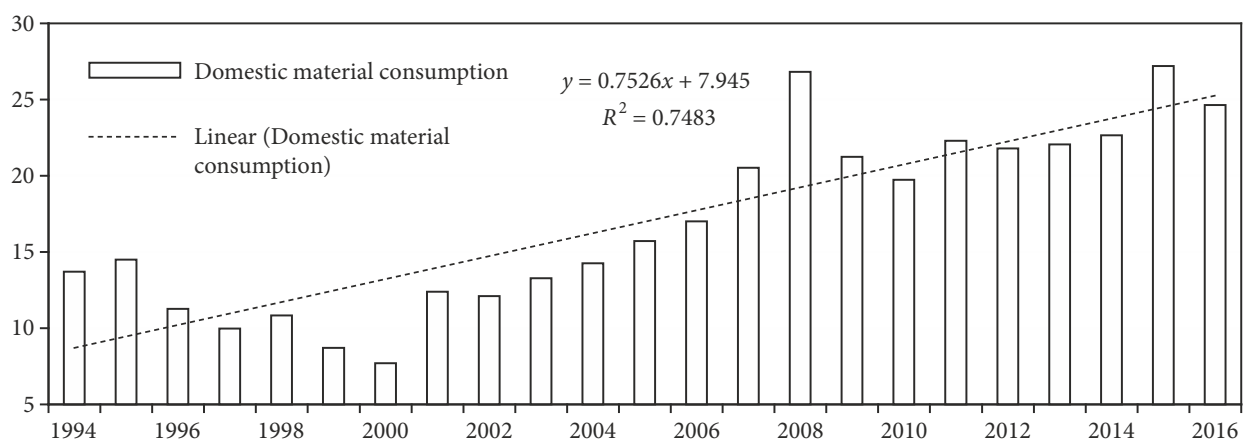

Figure 4. Domestic material consumption (tonnes per capita) (source: authors based on Eurostat, 2018) 
Energy use and domestic material consumption along with investments are decisive factors in shaping the production process as basically elements of production and all of them are influencing the economic efficiency levels and the economic gains. Thus, encompassing investments, energy use and domestic material consumption in a production function as Cobb-Douglas, provides a clear insight in understanding the dynamic relationships between these variables in generating national economic growth.

\section{Model and methodology}

As it has been previously established, the purpose of this study is to investigate impact of investments, energy use and domestic material consumption in changing of the Romanian economic paradigm. For achieving the research objectives, we have extended the conventional Cobb-Douglas aggregate production function by incorporating additional variables already described in Table 1. Most existing literature (Tiba \& Frikha, 2018; Narayan \& Doytch, 2017; Tiba, Omri, \& Frikha, 2016) test this determination by included other relevant variables beside capital and labor as traditional variables (Amri, 2016; Zhixin \& Xin, 2011; Wei, 2007).

Following the approach used by Solow (1956), and by Sturm and De Haan (2006), assuming the Hicksian neutrality of the technical progress (Wood \& Woods, 1989), there was considered as starting point the employing of the intensive form of the Cobb-Douglas function (Inada, 1963; Barelli \& Abreu Pessoâ, 2003):

$$
Y_{t}=A_{t} k_{t}^{\alpha}, 0<\alpha<1,
$$

where $A$ is the proportionality constant, comprising the stock of knowledge and technology; $k_{t}$ represents the capital stock per worker; and, by $\alpha$, was denoted the elasticity of capital stock per worker. The evolution of technical progress results from the initial stock of technology, $A_{0}$, of the time trend, $t$; following and extending the approach used by Rao (2010) there were considered two shift variables namely, the energy consumption per capita, eg, and the domestic material consumption per capita, $m c$, included in the equation (1), leading to:

$$
A_{t}=A_{0} \exp (\gamma t) \cdot e g_{t}^{\lambda} \cdot m c_{t}^{\mu} .
$$

In which, $\lambda$ and $\mu$ are the elasticities of energy consumption per capita and of the domestic material consumption per capita, respectively. From (1) and (2) results:

$$
Y_{t}=A_{0} \exp (\gamma t) \cdot k_{t}^{\alpha} \cdot e g_{t}^{\lambda} \cdot m c_{t}^{\mu},
$$

which, through linearization, becomes:

$$
\log \left(Y_{t}\right)=\log \left(A_{0}\right)+\gamma t+\alpha \log \left(k_{t}\right)+\lambda \log \left(e g_{t}\right)+\mu \log \left(m c_{t}\right) .
$$

The latest trends in analysis of the various connections of energies - namely, but not limited: economic growth, sustainable development, environmental taxation, etc. - suggest the usage of the vector error correction (VEC) model and the implied error correction term (ECT) (Narayan \& Smyth 2008; Constantini \& Martini, 2010; Al-mulali, Lee, Mohammed \& Sheau-Ting, 2013; Mirza \& Kanwal, 2017). This class of models is widely used in order to observe the changes within the behavioural and institutional changes, and to solve the 
situation of endogeneity between the variables, which represents a hypothesis that should be considered with a high degree of probability.

The VEC approach involves estimation of the long-term bi-variate relationship through including of lead and lags of the differenced explanatory variables, leading to better results in comparison to other competing techniques. As the cointegration relations are embedded within the VEC specification, they restrict the long-term evolution of the endogenous variables in order to converge to their cointegrating relationships, allowing for adjustments in short-run.

The cointegration term is called the error correction term, since the deviation from the long-term equilibrium is gradually corrected by a series of short-run partial adjustments. In estimation of the VEC models, a suitable approach is the GMM technique (Arellano \& Bover, 1995), which uses the lags of the endogenous variables as instruments for computing unbiased and consistent estimates. Starting from (4), the corresponding model can be specified upon the equations (5)-(8):

$$
\begin{aligned}
& \Delta \log y_{t}=\alpha^{y}+\left(\lambda_{1}+\mu_{1}\right) T+\beta^{y} E C T_{1, t-1}^{y}+\sum_{j=1}^{m} \delta_{1, j}^{y} \Delta \log y_{t-j}+\sum_{j=0}^{q_{1}} \varphi_{1, j}^{k} \Delta \log k_{t-j}+ \\
& \sum_{j=0}^{q_{2}} \sigma_{1, j}^{e g} \Delta \log e g_{t-j}+\sum_{j=0}^{q_{3}} \theta_{1, j}^{m c} \Delta \log m c_{t-j}+u_{1, t} ; \\
& \Delta \log k_{t}=\alpha^{k}+\left(\lambda_{2}+\mu_{2}\right) T+\beta^{k} E C T_{1, t-1}^{k}+\sum_{j=1}^{m} \delta_{2, j}^{y} \Delta \log y_{t-j}+\sum_{j=0}^{q_{1}} \varphi_{2, j}^{k} \Delta \log k_{t-j}+ \\
& \sum_{j=0}^{q_{2}} \sigma_{2, j}^{e g} \Delta \log e g_{t-j}+\sum_{j=0}^{q_{3}} \theta_{2, j}^{m c} \Delta \log m c_{t-j}+u_{2, t} ; \\
& \Delta \log e g_{t}=\alpha^{e g}+\left(\lambda_{3}+\mu_{3}\right) T+\beta^{e g} E C T_{1, t-1}^{e g}+\sum_{j=1}^{m} \delta_{3, j}^{y} \Delta \log y_{t-j}+\sum_{j=0}^{q_{2}} \varphi_{3, j}^{k} \Delta \log k_{t-j}+ \\
& \sum_{j=0}^{q_{1}} \sigma_{3, j}^{e g} \Delta \log e g_{t-j}+\sum_{j=0}^{q_{3}} \theta_{3, j}^{m c} \Delta \log m c_{t-j}+u_{3, t} ; \\
& \Delta \log m c_{t}=\alpha^{m c}+\left(\lambda_{4}+\mu_{4}\right) T+\beta^{m c} E C T_{1, t-1}^{m c}+\sum_{j=1}^{m} \delta_{4, j}^{y} \Delta \log y_{t-j}+\sum_{j=0}^{q_{1}} \varphi_{4, j}^{k} \Delta \log k_{t-j}+ \\
& \sum_{j=0}^{q_{2}} \sigma_{4, j}^{e g} \Delta \log e g_{t-j}+\sum_{j=0}^{q_{3}} \theta_{4, j}^{m c} \Delta \log m c_{t-j}+u_{4, t} .
\end{aligned}
$$

Testing for causality between the considered variables imply testing the significance of joint restrictions in equations (5)-(8). In (5), the short term causality from both $\log k_{t}$, $\log e g_{t}$ and $\log m c_{t-j}$ to $\log y_{t}$ implies that $\delta_{1, j}^{y}, \varphi_{1, j}^{k}, \theta_{1, j}^{m c} \neq 0,(\forall) j \neq 0$; the same condition applies for evaluation of the short-run causality described in each of the subsequent equations. The long term causality is subject to joint-evaluation of the significance and the right sign of the ECT (that is, negative, ensuring the convergence of the system to equilibrium), and of the number of cointegrating vectors in the system.

\section{Results and discussion}

The results refer to Romania, based on the data provided from the World Bank Database, Eurostat, International Labour Organization, and the National Institute of Statistics of Romania, and concern the GDP, the energy use, the domestic material consumption (both per 
capita), and the tangible fixed assets per worker. The GDP and the tangible fixed assets are in constant figures. The researches in the field of energy widely consider the explicit inclusion of the population among the explanatory variables; in the present study, the authors considered to include this variable implicitly, as all the variables are expressed per capita, or per worker, respectively.

Several studies have focused on finding direct correlations between GDP, labor and energy in developed countries, emphasizing the perception that energy can be considered as a fundamental component in production functions. In this context, Stern (2000) finds a deep cointegration between GDP, capital, labor and energy use in case of US economy during 1947-1994, arguing that energy is a factor which cannot be excluded from the cointegration equation. The same correlation is tested by Stresing, Lindenberger, and Kümmel (2008) in there developed countries as - Germany, Japan and US during an interval 1960-2008. Moreover, (Santos, Domingos, Sousa, \& St Aubyn, 2018) tests in their study the cointegrating relationships between combinations of output, capital, labor and energy for Portugal in the past 50 years. The results proof that energy could be employed as a classical production factor and engaged as a permanent component of Cobb-Douglas production function.

One of the key aspects that need to be checked is related to the independence of the considered variables. By providing the descriptive statistics and the correlation matrix of the datasets it is summarized the data available and used in the research and, also, it is highlighted the potential relationships between variables, as it is shown in Table 2.

The results of the partial correlation, presented in the Table 2 confirm the possibility to consider the domestic material consumption as a shift variable, besides the energy consumption, as these variables are not correlated. Although the results may indicate a possible endogeneity between the fixed capital per worker and the material consumption, the issue is fixed through the VEC model features, as they are presented above, within the methodological specifications.

Using of the VEC approach implies pre-testing of the considered variables, aimed to evidence their integration order, considering the specific tests, deployed either individually for each series (Augmented Dickey-Fuller (ADF) and Phillips-Perron (PP tests), either commonly using the IPS test and LLC tests (Im, Pesaran, \& Shin, 2003). The results of running of the unit root tests named above are presented in the Appendix (Table 7), and lead to the conclusion that the series are integrated of order one and suitable to further running of the cointegration tests. The Johansen's approach (1988) used in this respect, reported the results presented in the Appendix (Table 8). The results of the cointegration tests, confirm the presence of at most one cointegration relationship. The causality tests for the considered variables are presented in Appendix (Table 9).

In order to identify a possible and deep cointegration between the employed variables is necessary and usually implies applying the Granger-causality (Shahbaz, Jam, Bibi, \& Loganathan, 2016) which mainly reflects deep relations between the considered variables. As in Granger (2003), there is tested for causality in both directions, namely both variables act as the dependent variable as in Appendix, Table 10. The results presented in Appendix, Table 9 highlight a significant causality relationship that express the GDP represents the driver for the developments in both technical endowment of labour and material consumption; besides, 
Table 2. The descriptive statistics and the correlation matrix of the datasets (source: authors' processing based on WBD, Eurostat, ILO and NIS data)

\begin{tabular}{|c|c|c|c|c|}
\hline & $\operatorname{LOG}(Y)$ & LOG(EG) & $\mathrm{LOG}(\mathrm{K})$ & LOG(MC) \\
\hline Mean & 9.465 & 7.493 & 7.421 & 2.724 \\
\hline Median & 9.473 & 7.497 & 7.657 & 2.674 \\
\hline Maximum & 9.814 & 7.654 & 8.836 & 3.289 \\
\hline Minimum & 9.120 & 7.373 & 5.724 & 2.041 \\
\hline Std. Dev. & 0.257 & 0.081 & 0.894 & 0.351 \\
\hline Skewness & 0.014 & 0.198 & -0.497 & -0.217 \\
\hline Kurtosis & 1.325 & 2.280 & 2.218 & 2.011 \\
\hline Jarque-Bera & 2.455 & 0.591 & 1.400 & 1.019 \\
\hline Probability & 0.293 & 0.744 & 0.497 & 0.601 \\
\hline Sum & 198.773 & 157.357 & 155.841 & 57.196 \\
\hline Sum Sq. Dev. & 1.3176 & 0.1312 & 15.9949 & 2.4631 \\
\hline Observations & 21 & 21 & 21 & 21 \\
\hline \multicolumn{5}{|c|}{ Correlation matrix } \\
\hline & LOG(Y) & LOG $(\mathrm{K})$ & LOG(EG) & LOG(MC) \\
\hline \multirow{2}{*}{ LOG(Y) } & 1.000 & & & \\
\hline & --- & & & \\
\hline \multirow{2}{*}{ LOG $(\mathrm{K})$} & $0.912^{\star * *}$ & 1.000 & & \\
\hline & $(9.69)$ & ----- & & \\
\hline \multirow{2}{*}{ LOG(EG) } & -0.279 & -0.260 & 1.000 & \\
\hline & $(-1.26)$ & $(-1.17)$ & ----- & \\
\hline \multirow{2}{*}{ LOG(MC) } & $0.915^{* * *}$ & $0.818^{\star * \star}$ & -0.049 & 1.000 \\
\hline & $(9.89)$ & $(6.21)$ & $(-0.21)$ & $\begin{array}{ll}---- \\
-1\end{array}$ \\
\hline
\end{tabular}

Notes: t-statics in paranthesis; ${ }^{* \star}$ and ${ }^{\star *}$ indicates significance at $1 \%$ and $5 \%$ level.

the variable regarding the consumption of energy is not caused nor causes any of the other variables considered within the analysis.

Consequently, the using of the material consumption, besides the energy consumption as a shift variable in case of Romania represents a viable option. The Error-Correction-Term estimation for the VEC model, according to the Arellano-Bover approach, is presented in the Table 3.

The results in the estimated betas (ECTs) highlight that all the considered variables considered within the cointegrating relationship exert a significant and convergent influence towards achieving of the equilibrium of the system; the convergence is observed through the negative sign in case of all the coefficients. The slowest movement can be noticed in case of capital stock per worker, followed by the material consumption; instead, in case of the energy use the value of the coefficient, near to minus one, points out that, through the activity of the companies in the field a large percentage of disequilibrium is removed in each period. 
Table 3. Estimation of Error-Correction-Term in the Vector Error-Correction Model (source: authors' own processing)

\begin{tabular}{|c|c|c|c|c|}
\hline $\begin{array}{c}\text { Dependent } \\
\text { Variables }\end{array}$ & $\begin{array}{c}\text { ECT coefficients } \\
(t \text {-statistic })\end{array}$ & $\begin{array}{c}\text { Speed of adjustment } \\
(t \text {-statistic })\end{array}$ & $\begin{array}{c}\text { Lag coefficient } \\
(t \text {-statistic })\end{array}$ & $F$-statistic \\
\hline Y & - & $0.2757(2.226)^{* *}$ & $0.493(2.087)^{* * *}$ & 1.534 \\
\hline K & $-0.1893(-4.635)^{* * *}$ & $2.8707(2.684)^{* * *}$ & $0.032(1.389)$ & $2.526^{* *}$ \\
\hline EG & $-0.9599(-52.44)^{* *}$ & $0.3104(2.102)^{*}$ & $0.242(0.904)$ & 1.617 \\
\hline Mc & $-0.3087(-3.083)^{* * *}$ & $1.4919(4.099)^{* * *}$ & $-0.015(-0.208)$ & $5.480^{* * *}$ \\
\hline
\end{tabular}

Notes: Lag length: 1,$1 ;{ }^{* *},{ }^{* *},{ }^{*}$ indicates the significance at the 1,5 , and $10 \%$ levels of significance.

Further on, there have been examined the VEC causality results based on $\chi^{2}$ (Wald) tests and the reported results are presented in the Table 7 (see Appendix). According to the presented figures there is a causality from the technical endowment of labour to energy use (however, at $10 \%$ level of significance); from energy use to material consumption; also, it is noticeable the joint causality from all the considered variables to material consumption. The presented results support the conservation hypothesis, above asserted for the Romanian economy. The intensity of labour and energy use in Romanian economy proves that economy is a resource based economy, with doubtfully performance parameters.

The stability of the residuals are evaluated evaluate through the inverse roots stability plot; according to the results presented in the Figure 5, the roots have modulus less than one and lie inside the unit circle, that is, the estimated VEC model is stationary. Analytically, the lag structure of the VEC model is examined through Lag exclusion (Wald) test. The results presented in the Appendix, Table 7 (panel b) confirm the viability of the considered model; the insignificance of the technical endowment of labour appears as a result which may confirm,

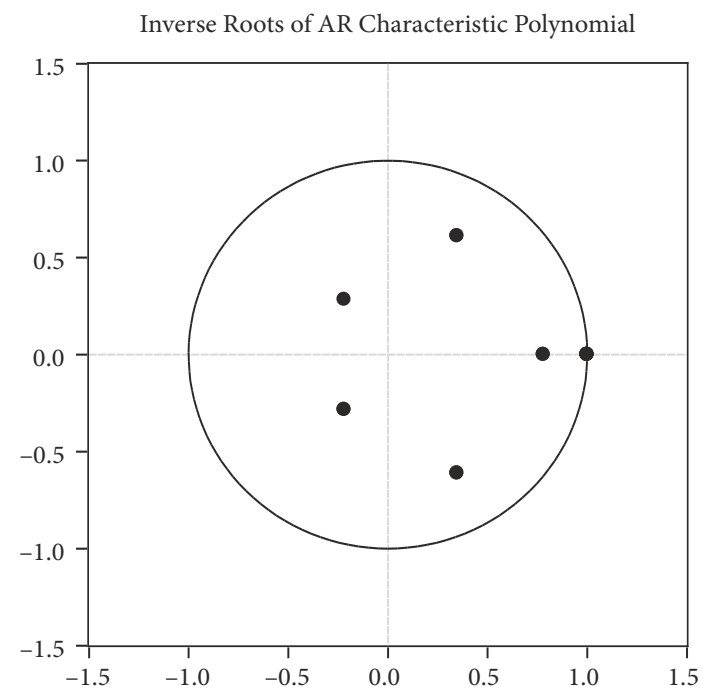

Figure 5. Inverse root stability plot for the estimated VEC model at 5\% (source: authors' own processing) 
amongst other results outlined in the present paper, the reduced capital, having as primarily cause the shortage in investments specific to Romanian economy.

Considering the standard triangular representation of the regression specification and assuming the existence of singular cointegrating vector (Phillips \& Hansen, 1990; Hansen, 1992), for a vectorial process $\left(y_{t}, X_{t}^{\prime}\right)$ associated to a $n+1$ dimension time series, the cointegrating equation can be written upon the form:

$$
y_{t}=X_{t}^{\prime} \beta^{\prime}+D_{1 t}^{\prime} \gamma_{1}+u_{1 t},
$$

in which, $D_{t}=\left(D_{1 t}^{\prime}, D_{2 t}^{\prime}\right)$ are the regressors corresponding to the deterministic trends, and the $n$-dimensional stochastic regressors $X_{t}$ are part of the equations system (10):

$$
\left\{\begin{array}{l}
X_{t}=\Gamma_{21}^{\prime} D_{1 t}+\Gamma_{22}^{\prime} D_{2 t}+\varepsilon_{2 t} . \\
\Delta \varepsilon_{2 t}=u_{2 t}
\end{array}\right.
$$

The $r_{1}$ - dimension vector of the $D_{1 t}$ exogenous variables, is part both of the regressors and the cointegrating equation, whilst the $r_{2}$ - dimensional of the deterministic trends, $D_{2 t}$, appears in the regressors equations, but it is excluded from the cointegrarating equation. If another regressor than the trend ones is present, it is presumed to belong to the $D_{1 t}$, implying that it does not belong to $D_{2 t}$.

Following the approach described by Hansen (1992), the innovations, $u_{t}=\left(u_{1 t}, u_{2 t}^{\prime}\right)^{\prime}$, are assumed to be strictly stationary and ergodic of zero mean. Compliant with $u_{t}$ are defined: the contemporaneous covariance matrix $\Sigma$, the one-sided long-run covariance matrix $\Lambda$, and the non-singular long-run covariance matrix $\Omega$, as follows:

$$
\begin{gathered}
\sum=E\left(u_{t} u_{t}^{\prime}\right)=\left[\begin{array}{ll}
\sigma_{11} & \sigma_{12} \\
\sigma_{21} & \sigma_{22}
\end{array}\right] ; \\
\Lambda=\sum_{j=0}\left(u_{t} u_{t-j}^{\prime}\right)=\left[\begin{array}{ll}
\lambda_{11} & \lambda_{12} \\
\lambda_{21} & \lambda_{22}
\end{array}\right] ; \\
\Omega=\sum_{j=0}\left(u_{t} u_{t-j}^{\prime}\right)=\left[\begin{array}{ll}
\omega_{11} & \omega_{12} \\
\omega_{21} & \omega_{22}
\end{array}\right]=\Lambda+\Lambda^{\prime}-\Sigma .
\end{gathered}
$$

Thereby, the hypotheses imply the vectors $y_{t}$ and $X_{t}$ are stationary and cointegrated, but exclude the cointegration between the elements of the $X_{t}$ matrix and the multi-cointegraration. According to the above considerations, in Figure 6 are presented the impulse responses (innovations) of the variables included in model; the impulses are equal to non-factorized standard deviation of the generating variable.

Concerning the speed of adjustment, the results express the significance of all the considered variables, confirming the results of the Johansen cointegration test. Based on the above results, there has been estimated the OLS equation. As the results of the unit root test indicate that both individual variables and their group are non-stationary, the estimation has been conducted considering the first differences of logarithms, upon the equation (14):

$$
\Delta \log y_{t}=\log A+\Delta \log k_{t}+\Delta \log e g_{t}+\Delta \log m c_{t}+\varepsilon_{t},
$$

with the results presented in Table 4 . 
Response of LOG(Y) to Nonfactorized One S.D. Innovations

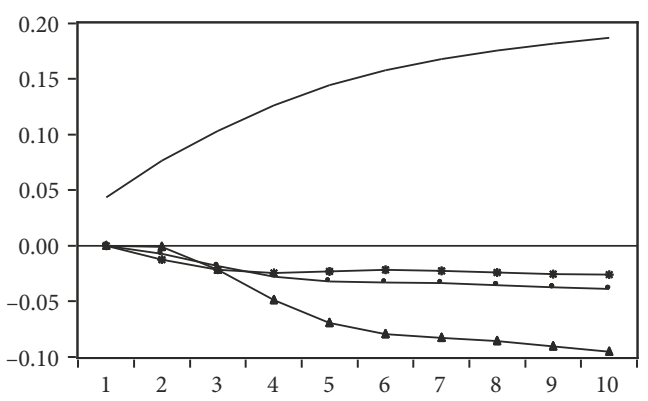

Response of LOG(EG) to Nonfactorized One S.D. Innovations

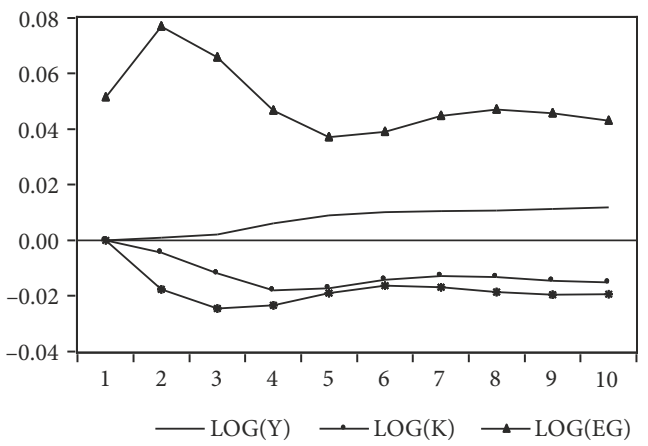

Response of LOG(K) to Nonfactorized One S.D. Innovations

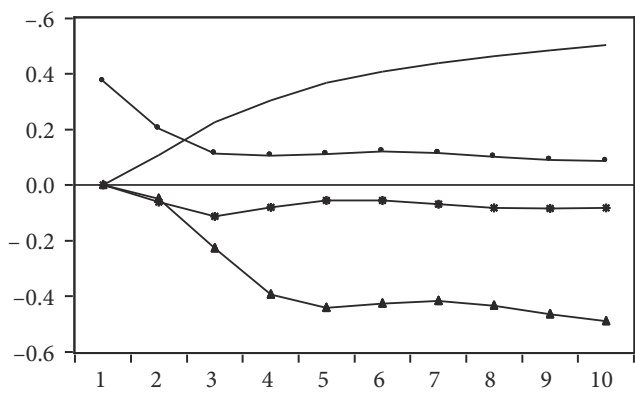

Response of LOG(MC) to Nonfactorized One S.D. Innovations

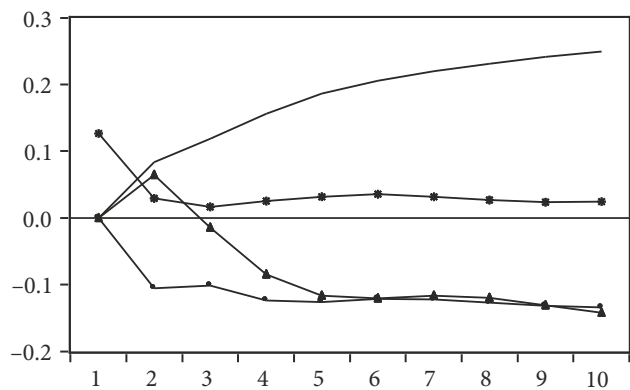

Figure 6. Response of variables to innovations - the impulses are equal to non-factorized standard deviation (source: authors' own processing)

Table 4. OLS regression results (source: authors' own processing)

\begin{tabular}{|l|c|}
\hline \multicolumn{1}{|c|}{ Variable } & Coefficient \\
\hline Constant & $0.035(4.722)^{\star * \star}$ \\
\hline $\mathrm{D}(\mathrm{LOG}(\mathrm{EG}))$ & $0.407(2.865)^{\star \star}$ \\
\hline $\mathrm{D}(\mathrm{LOG}(\mathrm{K}))$ & $0.007(0.453)$ \\
\hline $\mathrm{D}(\mathrm{LOG}(\mathrm{MC}))$ & $0.094(2.088)^{\star}$ \\
\hline F-statistic & $8.44^{\star * \star}$ \\
\hline
\end{tabular}

Note: the values in round brackets are the $t$-statistics; ${ }^{*},{ }^{* *},{ }^{* * *}$ indicate the coefficients which are statistically significant at $1,5,10 \%$, respectively; $F$-statistics is reported to test for the joint significance of the coefficients.

Although the VEC estimation proved the cointegration of all the considered variables, according to the OLS estimation, the technical endowment of labour appear to be statistically insignificant. The situation is also proved by the leverage plots of the considered regressors, presented in the Figure 7, which reveals the reduced slope of the technical fixed stock per worker besides the widespread of the scatter values. 
C

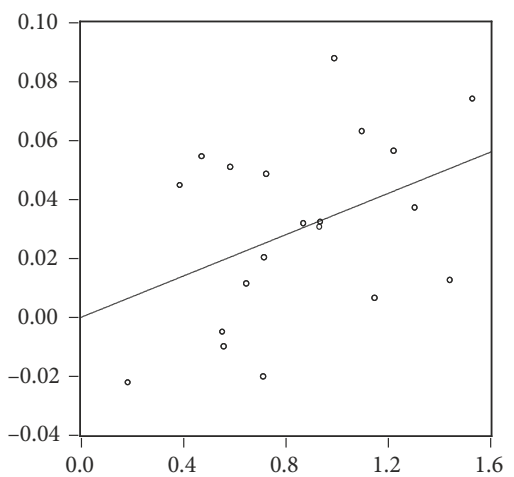

$\mathrm{D}(\mathrm{LOG}(\mathrm{EG}))$

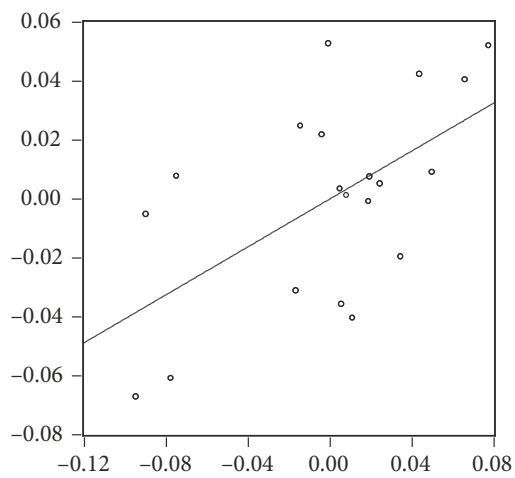

$\mathrm{D}(\mathrm{LOG}(\mathrm{K}))$

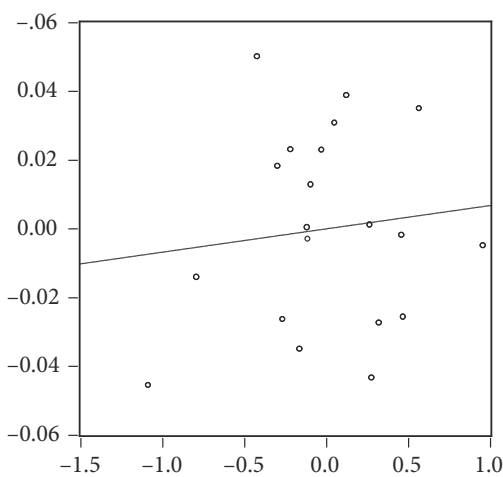

$\mathrm{D}(\mathrm{LOG}(\mathrm{MC}))$

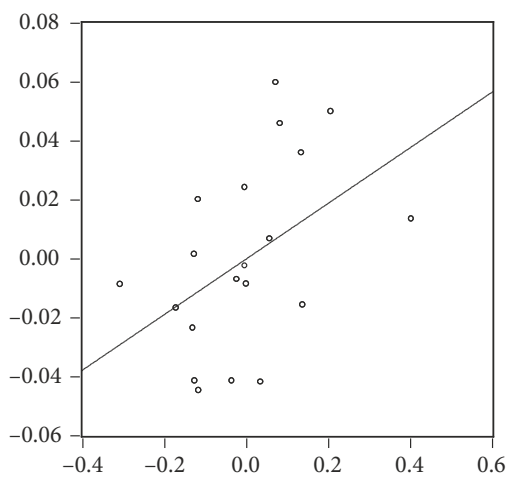

Figure 7. Leverage plots for Equation (9) (source: authors' own processing)

The stability of parameters has been evaluated through the plots of both CUSUM and CUSUMQ tests (Brown, Durbin, \& Evans, 1975). Having the recursive residuals defined upon the form:

$$
w_{t}=\frac{y_{t}-x_{t-1}{ }^{\prime} b}{\sqrt{\left(1+x_{t}{ }^{\prime}\left(X_{t-1}{ }^{\prime} X_{t-1}\right)^{-1} x_{t}\right)}},
$$

in which $x_{t}$ is the row matrix of the regressors for the period $t ; X_{t-1}$ represents the matrix $(t-1) \times k$ of regressors for the time range $1, \ldots, t-1$; and by $y_{t-1}$ is denoted the vector of observations on the endogenous variable. The estimated coefficient vector for the period $t-1$ is $b_{t-1}$. Based on the estimated coefficient vector is forecasted the value of $y_{t}$ equal to $x_{t}{ }^{\prime} b_{t-1}$. The cumulative sum of the recursive residuals is calculated upon the statistic:

$$
W_{t}=\sum_{r=k+1}^{t} \frac{w_{r}}{s},
$$

where $s$ represents the standard deviation of the recursive residuals. The statistic of the CUSUM of squares test is calculated upon: 


$$
S_{t}=\frac{\sum_{r=k+1}^{t} w_{r}^{2}}{\sum_{r=k+1}^{T} w_{r}^{2}} .
$$

The underlying idea of the second test is that, in general, the cumulative sum of squares lies within the $5 \%$ significance lines, suggesting the stability of the residual variance. The two tests (CUSUM and CUSUMQ) plot the cumulative sums of the recursive residuals alongside to the pair of $5 \%$ significance lines. The plots of the two tests are presented in the Figure 8.

As the cumulative sums for both tests presented in Figure 5 move inside the lane between the two critical lines, this suggests the joint stability of the parameters and of the variance for the analyzed estimation. Further, there has been considered the deepening of the analysis, through evaluation of the stability of each parameter using their recursive estimates. The respective plots allow tracking the evolution of the estimates for each coefficient in the equation for all feasible recursive estimations, within the lane of the two standard errors around the estimated coefficients. The recursive estimates of the coefficients in the Equation (14) are presented in Figure 9.
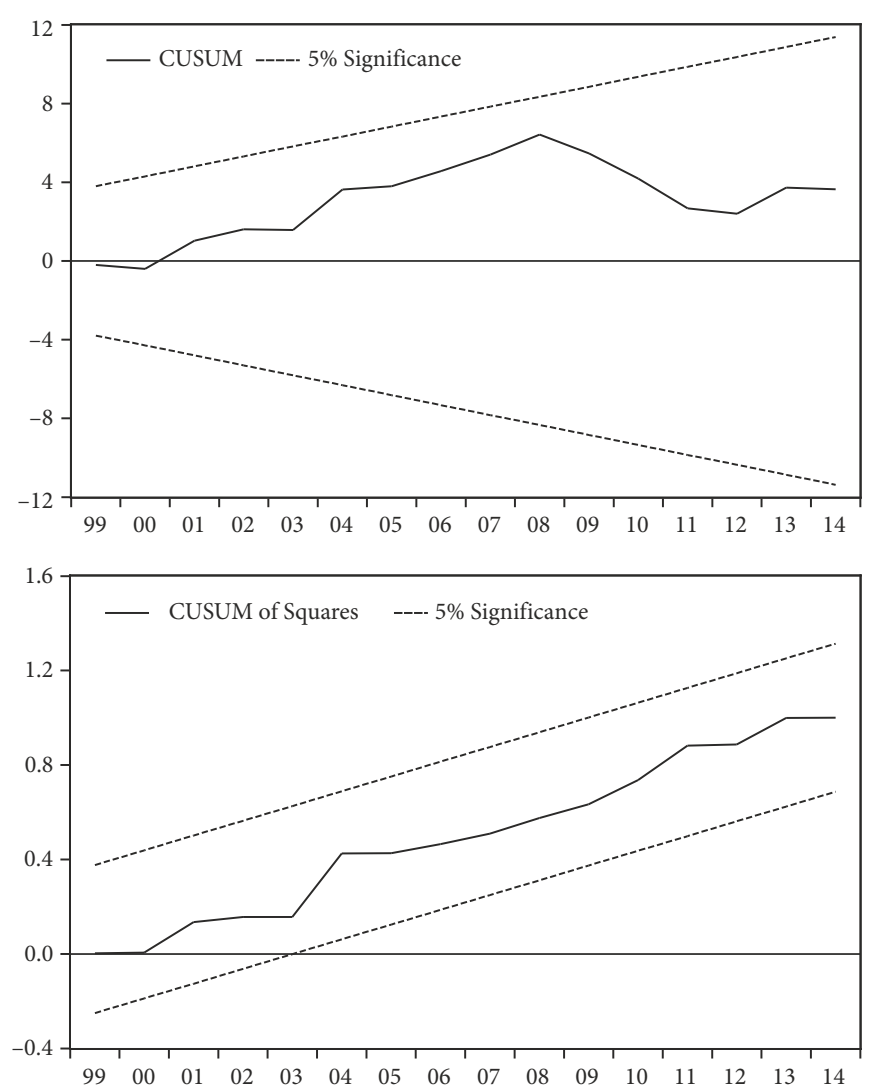

Figure 8. CUSUM and CUSUM squared tests (source: authors' own processing) 

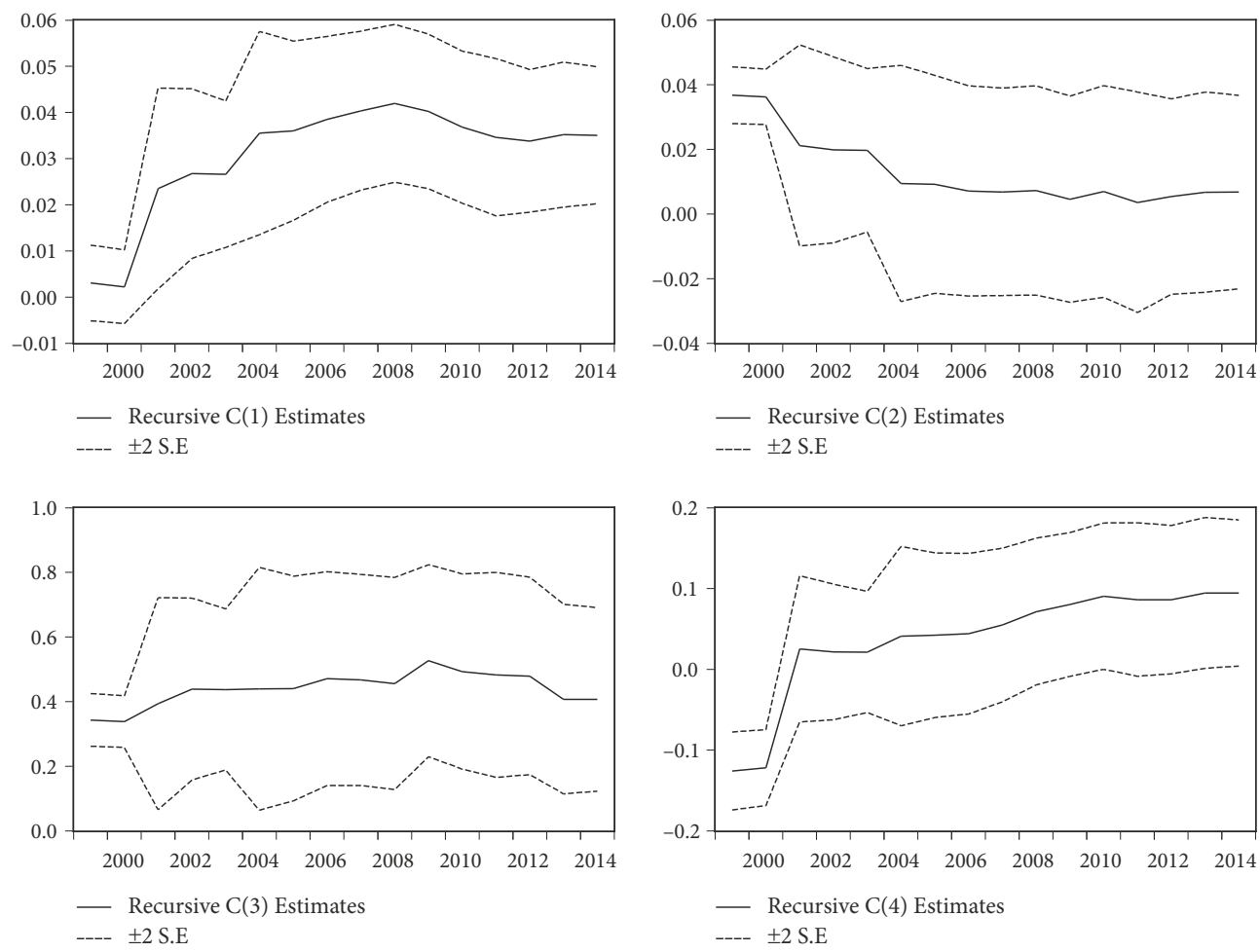

Figure 9. Recursive coefficient estimates for Equation (14) (source: authors' own processing)

The evaluation of the recursive estimates is similar to the CUSUM and CUSUM squared tests. The view in the Figure 6 suggests the stability of each estimated coefficients. Also, the quality of the estimation has been further subject of the diagnostic tests, namely: the Ramsey reset test, in order to detect of the omitted variables and the incorrect functional form; Breusch-Godfrey test, aimed to detect the residual autocorrelation; and the BreuschPagan-Godfrey test for heteroskedasticity. The statistics of the diagnostic tests are presented in the Table 5.

As there may be observed from the statistics presented in the Table 8 (see Appendix) and from the Figures 5, 6 and 7 respectively, both the diagnostic tests and the stability plots suggest the goodness-of-fit of the model. In order to view the structural changes, there has been considered the influence statistics method.

Table 5. Eq. (9) diagnostic tests (source: authors' own processing)

\begin{tabular}{|c|c|c|c|}
\hline Test Name & Null hypothesis & Test value & Probability \\
\hline Ramsey RESET & No omitted variables & $\mathrm{F}(1,15)=0.4399$ & 0.440 \\
\hline \multirow{2}{*}{ Breusch-Godfrey } & \multirow{2}{*}{$\begin{array}{l}\text { No residual } \\
\text { autocorrelation }\end{array}$} & $\mathrm{F}(2,14)=0.117$ & 0.890 \\
\hline & & $\chi^{2}(2)$ & 0.848 \\
\hline \multirow{2}{*}{ Breusch-Pagan-Godfrey } & \multirow{2}{*}{ Homoskedasticity } & $\mathrm{F}(3,16)=1.105$ & 0.376 \\
\hline & & $\chi^{2}(3)$ & 0.323 \\
\hline
\end{tabular}


Alike to leverage plots, the influence statistics is employed as a graphic technique for identifying of the outliers or influential observations, by measuring the difference induced by a single observation to the results of the regression. In this research, there have been considered RStudent, DFFITS, and CovRatio as the specific measures for the influence statistics. RStudent is a test for the significance of a particular observation, by calculating the studentized residual, upon the statistic:

$$
\bar{e}_{i}=\frac{e_{i}}{s(i) \cdot\left(1-h_{i}\right)^{1 / 2}},
$$

in which, by $e_{i}$ is denoted the actual residual for a particular observation, $s(i)$ represents the variance of the residuals that would result if the observation $i$ would not be included in the sample, and $h_{i}$ is the $i$-th diagonal element of the matrix $x_{i}\left(X^{\prime} X\right)^{-1} x_{i}$. DFFITS is the scaled difference in fitted values for a particular observation $i$, between the actual equation, and an equation estimated if the observation $i$ would be removed from the sample. The scaling is performed through dividing the difference by an estimate of the standard deviation for the fitted:

$$
\text { DFFITS }_{i}=\frac{e_{i}}{s(i) \cdot\left(1-h_{i}\right)^{1 / 2}} \sqrt{\frac{h_{i}}{1-h_{i}}} .
$$

COVRATIO is calculated as the ratio between the determinant of the covariance matrix of the coefficients of the actual equation and the determinant of the covariance matrix of the equation, the observation $i$ removed from the sample.

The plots of the influence statistics are presented in the Figure 10.
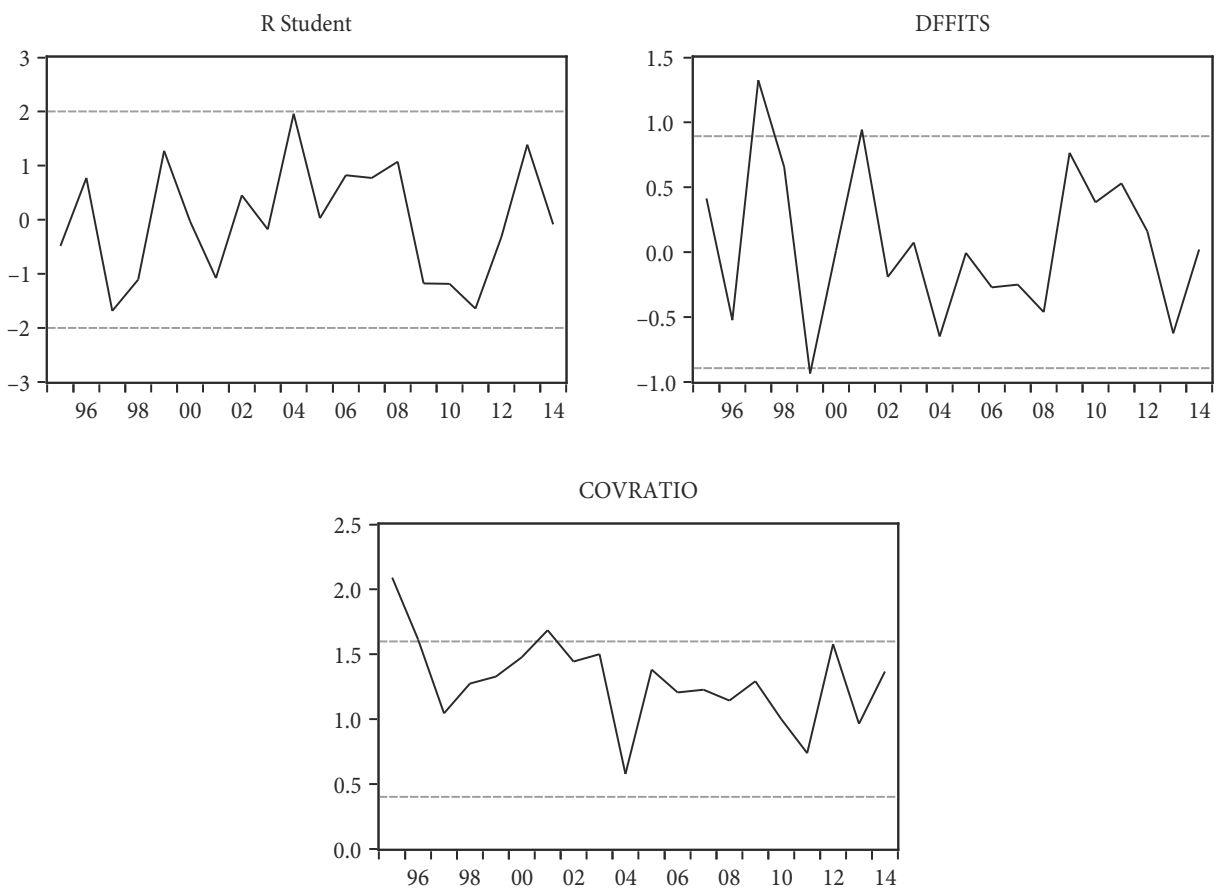

Figure 10. The influence statistics plots (source: authors' own processing) 
The graphs generally depict a continuously changing situation, which confirm the transitory situation of the economic structure via the specific consumption patterns. In the covratio graph, which presents the smoothest evolution, the year 2004 appears to suggest a structural break. Although the plots of the other considered statistics present multiple outliers, also the year 2004 appears to represent an influential observation, which may represent a structural break. Further, this observation it is subject to analytical evaluation through the Chow breakpoint test, under the null of no break point at specified dates.

The Chow breakpoint test is performed after partitioning the data into two subsamples. It fits the actual equation separately for each of the considered subsamples and reports the existence of significant differences in the estimated equations. A significant difference is considered to indicate a structural change in the relationship. The results of the Chow breakpoint test are presented in the Table 6 .

Table 6. Chow Breakpoint test (source: authors' own processing)

\begin{tabular}{|c|c|c|c|}
\hline Year & F-statistic & Log likelihood ratio & Wald Statistic \\
\hline 2000 & 1.309 & 7.240 & 5.234 \\
\hline 2001 & 1.325 & 7.316 & 5.300 \\
\hline 2002 & 2.338 & $11.526^{\star *}$ & 9.354 \\
\hline 2003 & $3.330^{\star *}$ & $14.933^{\star * *}$ & $13.319^{\star * *}$ \\
\hline 2004 & $4.037^{\star *}$ & $17.051^{\star * *}$ & $16.147^{\star * *}$ \\
\hline 2005 & 1.704 & 8.998 & 6.818 \\
\hline 2006 & 1.701 & 8.983 & 6.804 \\
\hline 2007 & 2.440 & $11.902^{\star *}$ & $9.759^{\star *}$ \\
\hline 2008 & 2.075 & $10515^{\star *}$ & 8.300 \\
\hline 2009 & 1.576 & 8.445 & 6.304 \\
\hline
\end{tabular}

Note: ${ }^{* *},{ }^{* *}$ indicate the statistics which are statistically significant at 1 , and $5 \%$, respectively.

For the Log likelihood ratio and the Wald Statistic, the probability is evaluated using the chi-square test.

The results of the Chow breakpoint test confirm that the years 2003-2004 as the moment of changing in the growth paradigm, as the statistics of all the considered tests are significant at minimum 5\% level. Thus, there are demonstrated some complex relations among energy, domestic material consumption and investments in the national economy of Romania.

\section{Conclusions}

The analysis carried out in this paper aimed at creating an overall picture of Romanian economic reforms and efforts following the process of becoming a free market economy. Hence, we have additionally considered energy use and domestic material consumption as variables in our empirical model to examine the impact of these variables on changing the Romanian economic paradigm. By focusing on the impact of fix capital, energy use and domestic material consumption, in this research it was identified cointegration relationships between economic output and all the production factors employed in the study, and it may be concluded 
that these relationships can be interpreted as economically meaningful by using the intensive form of the Cobb-Douglas function, which is if satisfying all the particular criteria requested during the research. This aspect was highlighted as a result of the data collection from 1990 to 2016, with a common period 1994-2014 in terms of economic development, investments and energy use. Although the Romania has experienced numerous reform periods, there are significant differences and transformations of the inland economic structure. The economic behavior patterns are highlighted by the percentage value fluctuations recorded in case of each indicator analyzed. The result of the above estimation emphasizes that the growth of the national economy, currently among highest levels in Europe, has in fact a predominant extensive character, based on consumption of resources. Also, during the research it was found economically plausible an intensive form of the Cobb-Douglas function for the model including energy, domestic material consumption and labor as factors of production, whether the energy and/or domestic material consumption are quality-adjusted or not.

Interestingly, the causal relationship from GDP to DMC is significant at $1 \%$, whilst the reverse causality is significant at only $10 \%$; in this situation, the remittances from abroad may be counted amongst the possible explanations. Considering also the results of the cointegration analysis, there may be observed the reduced role of the technical endowment of labor in the economic growth process, in case of Romania; this result express the needs of massive investments in the national economy, in order to ensure an intensive growth, within the capital to get the prevalent role.

\section{Acknowledgements}

The authors greatly acknowledge the participants of the International Conference "Information Society and Sustainable Development" - ISSD2017 for their precious inputs, critics and remarks in designing the very first darft of the manuscript. Authors also want to thank to the reviewers of the manuscript for their pertinent and useful remarks in improving the manuscript.

\section{Funding}

The manuscript founding is made from the author's personal funds.

\section{Author contributions}

The present form of the manuscript is the full result of the joint work of all the authors. All authors have equal contributions in designing, work conceptualization, data acquisition, analysis and interpretation of data and results, drafting the article. All the authors have intellectuality discussed and agreed to submit the manuscript.

\section{Disclosure statement}

The authors declare that they have no competing financial, professional, or personal interests from other parties. 


\section{References}

Ahmed, M., \& Azam, M. (2016). Causal nexus between energy consumption and economic growth for high, middle and low income countries using frequency domain analysis. Renewable and Sustainable Energy Reviews, 60, 653-678. https://doi.org/10.1016/j.rser.2015.12.174

Al-mulali, U., Lee, J. Y. M., Mohammed, A. H., \& Sheau-Ting, L. (2013). Examining the link between energy consumption, carbon dioxide emission, and economic growth in Latin America and the Caribbean. Renewable and Sustainable Energy Reviews, 26, 42-48. https://doi.org/10.1016/j.rser.2013.05.041

Amri, F. (2016). The relationship amongst energy consumption, foreign direct investment and output in developed and developing countries. Renewable and Sustainable Energy Reviews, 64, 694-702. https://doi.org/10.1016/j.rser.2016.06.065

Andrei, J.-V., Mieilă, M., Popescu, G., Nica, E., \& Manole, C. (2016). The impact and determinants of environmental taxation on economic growth communities in Romania. Energies, 9(11), 902. https://doi.org/10.3390/en9110902

Arellano, M., \& Bover, O. (1995). Another look at the instrumental variable estimation of error component models. Journal of Econometrics, 68(1), 29-51. https://doi.org/10.1016/0304-4076(94)01642-D

Barelli, P., \& Abreu Pessoâ, S. (2003). Inada conditions imply that production function must be asymptotically Cobb-Douglas. Economics Letters 81(3), 361-363.

https://doi.org/10.1016/S0165-1765(03)00218-0

Bastola, U., \& Sapkota, P. (2015). Relationships among energy consumption, pollution emission, and economic growth in Nepal. Energy, 80(1), 254-262. https://doi.org/10.1016/j.energy.2014.11.068

Brown, R. L., Durbin, J., \& Evans, J. M. (1975). Techniques for testing the constancy of regression relationships over time. Journal of the Royal Statistical Society. Series B (Methodological), 149-192.

Christiaans, T. (2011). Semi-endogenous growth when population is decreasing. Economics Bulletin, 31(3), 2667-2673.

Clark, J. (2017). Environmental Protection in Transition: Economic, Legal and Socio-Political Perspectives on Poland. UK: Taylor \& Francis. https://doi.org/10.4324/9781315256269

Constantini, V., \& Martini, C. (2010). The causality between energy consumption and economic growth: a multi-sectoral analysis using non-stationary cointegrated data. Energy Economics, 32(3), 591-603. https://doi.org/10.1016/j.eneco.2009.09.013

Costanza, R., Hart, M., Talberth, J., \& Posner, S. (2009). Beyond GDP: The need for new measures of progress (The Pardee papers No. 4). Boston University.

Eurostat (2018). The domestic material consumption (DMC). Retrieved 02 February 2018 from http:// ec.europa.eu/eurostat $/ \mathrm{tgm} /$ table.do?tab=table\&init $=1$ \&plugin $=1 \&$ language $=$ en $\&$ pcode $=\mathrm{t} 2020_{\text {_ }}$ rl110

Granger, C. W. (2003). Some aspects of causal relationships. Journal of Econometrics, 112(1), 69-69. https://doi.org/10.1016/S0304-4076(02)00148-3

Hansen, B. E. 1992. Tests for parameter instability in regressions with 1(1) processes. Journal of Business \& Economic Statistics, 10(3), 321-335.

Huang, B. N., Hwang, M. J., \& Yang, C. W. (2008). Causal relationship between energy consumption and GDP growth revisited: a dynamic panel data approach. Ecological Economics, 67(1), 41-54. https://doi.org/10.1016/j.ecolecon.2007.11.006

Im, K. S., Pesaran, M. H., \& Shin, Y. (2003). Testing for unit roots in heterogeneous panels. Journal of Econometrics, 115(1), 53-74. https://doi.org/10.1016/S0304-4076(03)00092-7

International Labour Organization [ILO]. (2018). Retrieved 03 Martch 2018 from https://www.ilo.org/ 
Inada, K.-I. (1963). On a two-sector model of economic growth: comments and a generalization. Review of Economic Studies 30(2), 119-127. https://doi.org/10.2307/2295809

Johansen, S. (1988). Statistical analysis of cointegration vectors. Journal of Economic Dynamics and Control, 12(2-3), 231-254. https://doi.org/10.1016/0165-1889(88)90041-3

Lan-yue, Z., Yao, L., Jing, Z., Bing, L., Ji-min, H., Shi-huai, D., ...\& Yuan-wei, L. (2017). The relationships among energy consumption, economic output and energy intensity of countries at different stage of development. Renewable and Sustainable Energy Reviews, 74, 258-264.

https://doi.org/10.1016/j.rser.2017.02.055

Mirza, F. M., \& Kanwal, A. (2017). Energy consumption, carbon emissions and economic growth in Pakistan: dynamic causality analysis. Renewable and Sustainable Energy Reviews, 72, 1233-1240. https://doi.org/10.1016/j.rser.2016.10.081

Narayan, P. K., \& Smyth, R. (2008). Energy consumption and real GDP in G7 countries: new evidence from panel cointegration with structural breaks. Energy Economics, 30(5), 2331-2341.

https://doi.org/10.1016/j.eneco.2007.10.006

Narayan, S., \& Doytch, N. (2017). An investigation of renewable and non-renewable energy consumption and economic growth nexus using industrial and residential energy consumption. Energy Economics, 68, 160-176. https://doi.org/10.1016/j.eneco.2017.09.005

National Institute of Statistics of Romania [NIS]. (2018). Retrieved 03 March 2018 from http://www. insse.ro

Panayotou, T. (2016). Economic growth and the environment. In N. Haenn, A. Harnish, R. Wilk (Eds.), The environment in anthropology (2nd ed., pp.140-148). New York: NYU Press.

Pang, R. Z., Deng, Z. Q., \& Hu, J. L. (2015). Clean energy use and total-factor efficiencies: An international comparison. Renewable and Sustainable Energy Reviews, 52, 1158-1171. https://doi.org/10.1016/j.rser.2015.08.002

Payne, J. E. (2010). A survey of the electricity consumption-growth literature. Applied Energy, 87(3), 723-731. https://doi.org/10.1016/j.apenergy.2009.06.034

Phillips, P., \& Hansen, B. E. (1990). Statistical inference in instrumental variables regression with I(1) processes. Review of Economic Studies, 57(1), 99-125. https://doi.org/10.2307/2297545

Popescu, G., Mieilă, M., Nica, E., \& Andrei J.-V. (2018). The emergence of the effects and determinants of the energy paradigm changes on European Union economy. Renewable and Sustainable Energy Reviews, 81(Part1), 768-774. https://doi.org/10.1016/j.rser.2017.08.055

Sachs, W. (2015). Planet dialectics: Explorations in environment and development. UK, London: Zed Books Ltd.

Santos, J., Domingos, T., Sousa, T., \& St Aubyn, M. (2018). Useful exergy is key in obtaining plausible aggregate production functions and recognizing the role of energy in economic growth: Portugal 1960-2009. Ecological Economics, 148, 103-120. https://doi.org/10.1016/j.ecolecon.2018.01.008

Shahbaz, M., Jam, F. A., Bibi, S., \& Loganathan, N. (2016). Multivariate Granger causality between CO2 emissions, energy intensity and economic growth in Portugal: Evidence from cointegration and causality analysis. Technological and Economic Development of Economy, 22(1), 47-74. https://doi.org/10.3846/20294913.2014.989932

Soava, G., Mehedintu, A., Sterpu, M., \& Raduteanu, M. (2018). Impact of renewable energy consumption on economic growth: evidence from European Union countries. Technological and Economic Development of Economy, 24(3), 914-932. https://doi.org/10.3846/tede.2018.1426

Solow, R. M. (1956). A contribution to the theory of economic growth. Quarterly Journal of Economics 70(1), 65-94. https://doi.org/10.2307/1884513

Stern, D. I. (2000). A multivariate cointegration analysis of the role of energy in the US macroeconomy. Energy Economics, 22(2), 267-283. https://doi.org/10.1016/S0140-9883(99)00028-6 
Stresing, R., Lindenberger, D., \& Kümmel, R. (2008). Cointegration of output, capital, labor, and energy. The European Physical Journal B, 66(2), 279-287. https://doi.org/10.1140/epjb/e2008-00412-6

Sturm, J.-E., De Haan, J. (2006). Public capital spending in The Netherlands: developments and explanations. Applied Economics Letters 5(1), 5-10. https://doi.org/10.1080/758540117

Tiba, S., \& Frikha, M. (2018). Income, trade openness and energy interactions: Evidence from simultaneous equation modeling. Energy, 147, 799-811. https://doi.org/10.1016/j.energy.2018.01.013

Tiba, S., Omri, A., \& Frikha, M. (2016). The four-way linkages between renewable energy, environmental quality, trade and economic growth: A comparative analysis between high and middle-income countries. Energy Systems, 7(1), 103-144. https://doi.org/10.1007/s12667-015-0171-7

Wei, T. (2007). Impact of energy efficiency gains on output and energy use with Cobb-Douglas production function. Energy Policy, 35(4), 2023-2030. https://doi.org/10.1016/j.enpol.2006.08.009

Wood, J. C., \& Woods, R. N. (1989). Sir John R. Hicks: Critical assessments. London: Rutledge.

World Bank Database. (2018a). Retrieved 03 March 2018 from https://data.worldbank.org/indicator/ EG.USE.PCAP.KG.OE?locations $=$ RO

World Bank Database. (2018b). Retrieved from https://data.worldbank.org/indicator/NY.GDP.PCAP. $\mathrm{KN}$ ?locations $=\mathrm{RO}$

Zaharia, M., Pătrașcu, A., Gogonea, M. R., Tănăsescu, A., \& Popescu, C. (2017). A cluster design on the influence of energy taxation in shaping the new EU-28 economic paradigm. Energies, 10(2), 257. https://doi.org/10.3390/en10020257

Zhixin, Z., \& Xin, R. (2011). Causal relationships between energy consumption and economic growth. Energy Procedia, 5, 2065-2071. https://doi.org/10.1016/j.egypro.2011.03.356

Zilio, M., \& Recalde, M. (2011). GDP and environment pressure: the role of energy in Latin America and the Caribbean. Energy Policy, 39(12), 7941-7949. https://doi.org/10.1016/j.enpol.2011.09.049

\section{APPENDIX}

Table 7. Unit root tests (source: authors' processing based on WBD, Eurostat, ILO and NIS data)

\begin{tabular}{|l|c|c|c|c|c|c|c|c|}
\hline \multicolumn{1}{|c|}{ Variable } & \multicolumn{2}{|c|}{ LLC } & \multicolumn{2}{c|}{ IPS } & \multicolumn{2}{c|}{$\begin{array}{c}\text { ADF-Fisher } \\
\text { Chi-square }\end{array}$} & \multicolumn{2}{c|}{$\begin{array}{c}\text { PP-Fisher } \\
\text { Chi-square }\end{array}$} \\
\hline & Level & Differenced & Level & Differenced & Level & Differenced & Level & Differenced \\
\hline LOG(Y) & -0.014 & -0.55 & -0.45 & $-3.77^{* *}$ & 0.885 & 0.01 & 0.975 & 0.01 \\
\hline LOG(K) & -0.202 & -1.67 & -1.53 & $-5.32^{* * *}$ & 0.504 & 0.00 & 0.482 & 0.00 \\
\hline LOG(EG) & -0.040 & -0.55 & -1.03 & $-3.90^{* * *}$ & 0.733 & 0.00 & 0.842 & 0.00 \\
\hline LOG(MC) & -0.080 & -1.10 & -0.77 & $-4.74^{* * *}$ & 0.808 & 0.00 & 0.820 & 0.00 \\
\hline \hline LLC t-stat & 0.143 & $-5.16^{* * *}$ & & & & & & \\
\hline IPS W-stat & & & 1.26 & $-6.41^{* * *}$ & & & & \\
\hline ADF-Fisher Chi-square & & & 2.67 & $50.07^{* *}$ & 2.25 & $65.85^{* * *}$ \\
\hline ADF-Choi z-stat & & & & 1.35 & $-5.73^{* * *}$ & 1.92 & $-6.60^{* * *}$ \\
\hline
\end{tabular}

Notes: No individual trends constant term ("fixed effects") included in tests equations.

The results for ADF-Fisher Chi-square and PP-Fisher Chi-square tests are the corresponding probabilities under the null of unit root.

Differenced refers to series resulted from first-difference.

${ }^{* * *}$ and ${ }^{* *}$ indicate the significance at 1 and $5 \%$ levels of confidence. 
Table 8. Johansen cointegration test (source: authors' processing based on WBD, Eurostat, ILO and NIS data)

\begin{tabular}{|l|c|c|c|c|}
\hline Hypothesized No. of CE(s) & Eigenvalue & Trace Statistic & 0.05 Critical Value & Probability \\
\hline \multicolumn{5}{|c|}{ LOG(Y) LOG(K) LOG(EG) LOG(MC) } \\
\hline None $^{*}$ & 0.952884 & 84.60311 & 40.17493 & $<0.01$ \\
\hline At most ${ }^{*}$ & 0.748778 & 32.66566 & 24.27596 & $<0.01$ \\
\hline At most 2 & 0.416991 & 9.181522 & 12.3209 & 0.1587 \\
\hline At most 3 & 0.000537 & 0.009136 & 4.129906 & 0.938 \\
\hline \hline \multirow{2}{*}{ Hypothesized No. of CE(s) } & Eigenvalue & $\begin{array}{c}\text { Max-Eigen } \\
\text { Statistic }\end{array}$ & 0.05 Critical Value & Probability \\
\hline \multicolumn{5}{|c|}{ LOG(Y) LOG(K) LOG(EG) } \\
\hline None * & 0.952884 & 51.93746 & 24.15921 & $<0.01$ \\
\hline At most $1 *$ & 0.748778 & 23.48414 & 17.7973 & $<0.01$ \\
\hline At most 2 & 0.416991 & 9.172386 & 11.2248 & 0.1124 \\
\hline At most 3 & 0.000537 & 0.009136 & 4.129906 & 0.938 \\
\hline
\end{tabular}

Table 9. The results of the pairwise Granger causality tests (source: authors' own processing)

\begin{tabular}{|c|c|c|c|c|}
\hline Test statistic & Y & K & EG & MC \\
\hline Y & & $5.357^{* *}$ & 0.787 & $15.40^{* *}$ \\
\hline K & 0.891 & & 1.044 & 0.551 \\
\hline EG & 2.072 & 0.573 & & 1.244 \\
\hline MC & $3.462^{*}$ & 1.322 & 1.544 & \\
\hline
\end{tabular}

Notes: In the first columns, the explanatory variable in the causality relation; in the headings, the dependent variables; ${ }^{* *}$ Indicates rejection of the null hypothesis of no causality at the at the 1,5 , and $10 \%$ levels of significance.

Table 10. Granger causality and lag exclusion test results for the estimated Vector Error-Correction Model

\begin{tabular}{|l|c|c|}
\hline \multicolumn{1}{|c|}{ Excluded } & Test Statistic $\left(\chi^{2}\right)$ & \\
\hline \multicolumn{2}{|c|}{ Panel a: Granger causality results (Wald test) } & Probability \\
\hline \multicolumn{2}{|c|}{ Dependent variable: D(LOG(Y)) } \\
\hline D (LOG(K)) & 1.931 & 0.165 \\
\hline D (LOG(EG)) & 0.817 & 0.366 \\
\hline D (LOG(MC)) & 0.043 & 0.835 \\
\hline Joint & 2.361 & 0.501 \\
\hline & 0.032 & 0.858 \\
\hline D $($ LOG $(Y))$ & 0.587 & 0.444 \\
\hline D (LOG(EG)) & 0.461 & 0.497 \\
\hline D (LOG(MC)) & 3.563 & 0.6366 \\
\hline Joint & Dependent variable: $\Delta(\mathrm{LOG}(\mathrm{K}))$ & \\
\hline
\end{tabular}


End of Table 10

\begin{tabular}{|l|c|c|}
\hline \multicolumn{2}{|c|}{ Excluded } & Test Statistic $\left(\chi^{2}\right)$ \\
\hline \multicolumn{2}{|c|}{ Dependent variable: $\Delta(\mathrm{LOG}(\mathrm{EG}))$} & 0.2989 \\
\hline $\mathrm{D}(\mathrm{LOG}(\mathrm{Y}))$ & 1.079 & 0.0914 \\
\hline $\mathrm{D}(\mathrm{LOG}(\mathrm{K}))$ & $2.850^{*}$ & 0.5965 \\
\hline $\mathrm{D}(\mathrm{LOG}(\mathrm{MC}))$ & 0.280 & 0.313 \\
\hline Joint & 3.563 & 0.5166 \\
\hline \multicolumn{2}{|c|}{ Dependent variable: $\Delta(\mathrm{LOG}(\mathrm{MC}))$} & 0.9927 \\
\hline $\mathrm{D}(\mathrm{LOG}(\mathrm{Y}))$ & 0.421 & 0.0006 \\
\hline $\mathrm{D}(\mathrm{LOG}(\mathrm{K}))$ & $11.632^{* * *}$ & 0.0017 \\
\hline $\mathrm{D}(\mathrm{LOG}(\mathrm{EG}))$ & $15.17^{* * *}$ & $p$-value \\
\hline Joint & $\chi^{2}(4)=15.886^{* * *}$ & $<0.01$ \\
\hline & $\chi^{2}(4)=2.075$ & 0.722 \\
\hline $\mathrm{D}(\mathrm{LOG}(\mathrm{Y}))$ & $\chi^{2}(4)=7.761^{*}$ & 0.100 \\
\hline $\mathrm{D}(\mathrm{LOG}(\mathrm{K}))$ & $\chi^{2}(4)=15.207^{* * *}$ & $<0.01$ \\
\hline $\mathrm{D}(\mathrm{LOG}(\mathrm{EG}))$ & $\chi^{2}(16)=43.561^{* * *}$ & $<0.01$ \\
\hline $\mathrm{D}(\mathrm{LOG}(\mathrm{MC}))$ & & \\
\hline Joint & Panel b: Lag exclusion $(\mathrm{Wald})$ test & \\
\hline
\end{tabular}

